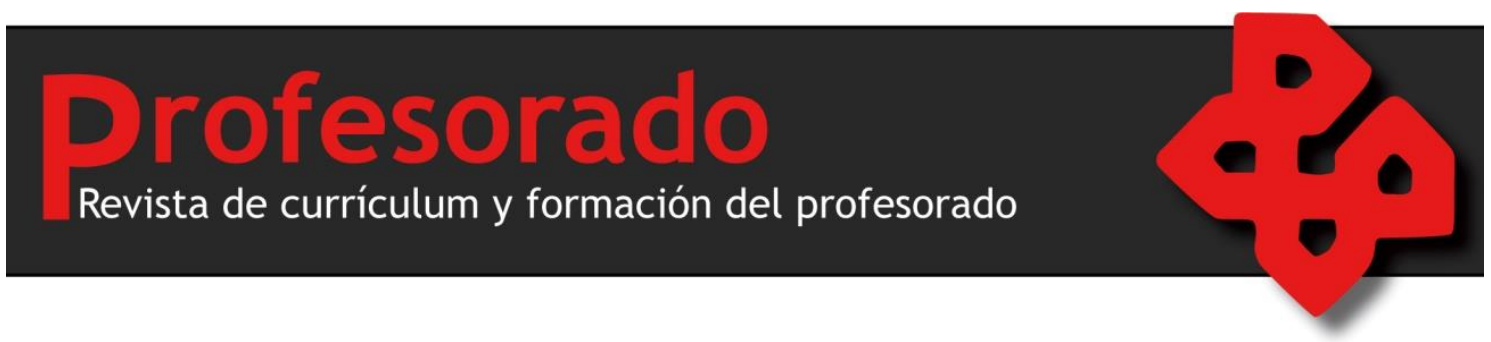

VOL.24, No1 (Febrero, 2020)

ISSN 1138-414X, ISSNe 1989-6395

DOI: $10.30827 /$ profesorado.v24i1.8834

Fecha de recepción: 28/02/2019

Fecha de aceptación: 04/11/2019

\title{
DESIGUALDADES EDUCATIVAS Y RESPUESTA INSTITUCIONAL: UNA INVESTIGACIÓN DESDE LA PERSPECTIVA TERRITORIAL
}

\author{
Educational inequalities and institutional response: $A$ research from the \\ territorial perspective
}

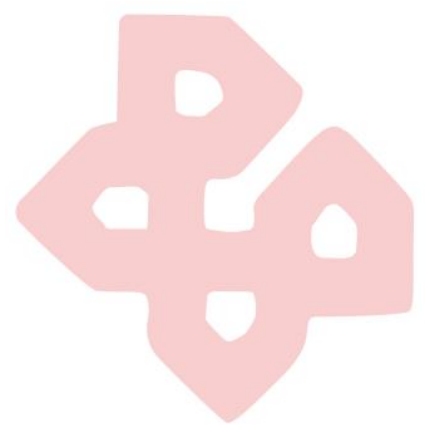

\author{
Eduardo Romero-Sánchez, Salvador Alcaraz-García \\ y Manuel Hernández-Pedreño \\ Universidad de Murcia \\ E-mail: eromero@um.es ; sag@um.es ; \\ manuel@um.es \\ ORCID ID: https://orcid.org/0000-0001-5090-0961 \\ https://orcid.org/0000-0001-8590-8912 \\ https://orcid.org/0000-0001-5243-0481
}

\section{Resumen:}

España presenta altos niveles de desigualdad territorial en materia educativa. Aunque durante el periodo reciente se han mejorado los resultados y reducido las distancias, aún persisten valores muy dispares según el territorio, vinculados, en gran medida, con los niveles de riqueza y de desarrollo socioeconómico. No obstante, también inciden otros factores culturales derivados de la composición y diversidad de la población. Esta investigación analiza, desde una perspectiva socioeducativa, los distintos sistemas educativos autonómicos que existen en nuestro país a través de los siguientes objetivos: conocer las distancias en los resultados educativos entre las distintas autonomías y la conexión con sus contextos socioeconómicos; profundizar en las principales variables sociodemográficas vinculadas al fracaso y al abandono escolar y valorar la respuesta institucional autonómica ofrecida en materia de política educativa. La estrategia metodológica empleada es mixta, complementando fuentes primarias (entrevistas a profesionales) y secundarias (análisis estadístico, revisión de estudios y análisis documental). Los resultados evidencian que las autonomías configuran 
su política educativa con diferentes niveles de gasto en educación y con distintas bases documentales. Tras el análisis de las variables implicadas en la conformación de los modelos de respuesta institucional, se han diferenciado seis tipos de estrategias socioeducativas, con distintos niveles de eficacia y eficiencia. En definitiva, España presenta un escenario educativo donde conviven grandes disparidades territoriales, tanto en los resultados como en las medidas de intervención, lo que dificulta en gran medida la cohesión social.

Palabras clave: abandono escolar temprano; desigualdad educativa; desigualdad territorial; fracaso escolar; política educativa; resultados educativos

\begin{abstract}
:
Spain has high levels of territorial inequality in education. Although the results have been improved during the recent period and the distances reduced, there are still very different values depending on the territory, linked, to a large extent, with the levels of wealth and socioeconomic development. This research analyzes, from a socioeducational perspective, the different autonomous educational systems that exist in our country through the following objectives: to know the distances in the educational results between the different autonomies and the connection with their socioeconomic contexts; deepen the main sociodemographic variables linked to school failure and dropout and assess the autonomic institutional response offered in terms of educational policy. The methodological strategy used is mixed, complementing primary (interviews with professionals) and secondary (statistical analysis, review of studies and documentary analysis) sources. The results show that the autonomies configure their educational policy with different levels of expenditure on education and with different documentary bases. Following the analysis of the variables involved in the conformation of the institutional response models, six types of socio-educational strategies have been differentiated, with different levels of effectiveness and efficiency. In short, Spain presents an educational scenario where large territorial disparities coexist, both in the results and in the intervention measures, which greatly hinders social cohesion.
\end{abstract}

Key words: educational inequality; educational policy; educational results; early school dropouts; school failure; territorial inequality

\title{
1. Presentación
}

A partir del análisis de los distintos componentes que intervienen en el desarrollo de las políticas educativas, este trabajo ${ }^{1}$ pretende profundizar en las causas que explican las desigualdades educativas que existen en España y sus distintas autonomías. Para ello, se consideran una serie de indicadores de resultados, de la gestión y del gasto educativo, junto a otros de desarrollo económico o niveles de riqueza y pobreza. Asimismo, el estudio se complementa con el análisis documental de la respuesta institucional autonómica², al tiempo que han sido consultados una serie de profesionales que intervienen tanto en la concepción, como en el diseño e implementación de las políticas socioeducativas.

\footnotetext{
${ }^{1}$ Este trabajo se deriva del Proyecto de Investigación “Inserción sociolaboral de la juventud en España y la Región de Murcia" desarrollado y financiado desde el Observatorio de la Exclusión Social de la Universidad de Murcia (OES).

${ }^{2}$ Cuando hablamos de análisis documental de la respuesta institucional nos referimos al análisis de la normativa, los planes o los programas desarrollados en materia de política educativa por las distintas administraciones autonómicas.
} 
Las profundas desigualdades territoriales educativas en España se evidencian a través de multitud de indicadores y persisten en el tiempo, a pesar de haber llevado a cabo distintas intervenciones sobre varios elementos del sistema educativo (Foces, 2018). Estas actuaciones, tendentes a mejorar los resultados educativos, presentan una gran heterogeneidad entre autonomías, encontrando territorios donde existe un alto compromiso documental con el abandono y el fracaso escolar, mientras otros apenas cuentan con programas e iniciativas en este ámbito. Sin duda, esta mayor o menor implicación institucional también se manifiesta a través de la inversión autonómica en educación. La realidad es que en España conviven comunidades con muy diferentes resultados educativos, los cuales no siempre se relacionan con la inexistencia de una política educativa regional, ya sea en materia documental o de inversión pública. No obstante, sí encontramos cierta correlación entre los niveles de riqueza/pobreza autonómicos y los resultados del sistema educativo.

Los resultados confirman que, en el periodo de análisis 2007-2016, si bien se han producido ciertas mejoras en los resultados educativos en todas las autonomías, se mantienen las distancias entre ellas en la mayoría de los indicadores contemplados. Se confirma la importante relación entre resultados educativos deficientes y niveles de pobreza altos, al tiempo que se observa un retroceso en las políticas autonómicas, reflejado en un descenso del gasto público en educación en todas ellas.

Las conclusiones obtenidas permiten definir seis modelos diferenciados de políticas educativas resultantes de la implementación de diferentes estrategias de gestión, compromiso documental y nivel de gasto público. No obstante, los resultados educativos no siempre se corresponden con mayores niveles de compromiso o de gasto educativo. Sin duda, otras variables territoriales (culturales, sociales y económicas) deberán ser tenidas en cuenta.

\section{Justificación del problema}

Existe un gran consenso social y científico en torno a la idea de que un mayor nivel educativo genera, por lo general, una mayor capacidad resolutiva en los diferentes aspectos de la vida. En este sentido, una sociedad mejor formada implica una sociedad que progresa tanto social como económicamente (Gil-Lacruz y Gil-Lacruz, 2006). Entre las principales formulaciones planteadas para explicar la relación existente entre la educación y el crecimiento económico destaca la teoría del capital humano. La acumulación de inversiones, tales como la educación y la formación en el trabajo, sirve para producir bienes y servicios, determinando la productividad y el bienestar de los individuos en una sociedad (Briceño-Mosquera, 2011). Durante las décadas de los años sesenta y setenta del pasado siglo es indiscutible la notoriedad y hegemonía que alcanzaron estas tesis a nivel internacional en todos los foros de economía de la educación (Becker, 1964; Mincer, 1958; Schultz, 1961), generando un amplio consenso sobre los efectos positivos de la educación, especialmente por su contribución al crecimiento y desarrollo del sistema productivo. Sin embargo, a partir de la década de los ochenta se empieza a cuestionar la validez explicativa de dicho 
modelo al entrar en un contexto socioeconómico caracterizado por la crisis de la economía occidental, el crecimiento del desempleo y los cambios en la organización productiva, propiciados principalmente por la innovación tecnológica.

A pesar de todo, la inversión en capital humano se encuentra en el centro de las estrategias de los países de la OCDE para promover la prosperidad económica, el pleno empleo y la cohesión social. Los individuos, las organizaciones y las naciones reconocen de manera crecien que los altos niveles de conocimiento, habilidades y competencias son esenciales para asegurar un futuro exitoso (OCDE, 1998). Por tanto, la formación se considera un importante factor de protección del riesgo social (Fundación FOESSA, 2014; Hernández, 2010). Así lo corroboran recientes estudios, estableciendo correlaciones positivas entre el origen social y el estatus familiar del alumnado y los resultados educativos (Martínez, 2017; Salido y Martínez, 2018). En esta misma línea, Villar (2012) establece una vinculación entre los resultados educativos (en pruebas internacionales como PISA y en cifras de permanencia del alumnado en el sistema educativo) y el desarrollo económico de las regiones (en generación de riqueza, renta per cápita y fortaleza del mercado (aboral). Como ya expresaba Solano (2008) la educación puede tener dos caras, una que perpetúe las desigualdades sociales y otra que favorezca la promoción social, ya que, aunque no supone una solución total a las diferencias de origen social, sí que proporciona, en ocasiones, grandes oportunidades de compensación de las deficiencias culturales que devienen del origen social y familiar de una persona.

El caso español es de especial singularidad en el contexto de países de la OCDE, debido al importante déficit de formación y cualificación del capital humano que presenta y a las amplias diferencias existentes entre sus distintas comunidades autónomas (Guisán, Neira y Aguayo, 1998), presentándose la lucha por frenar el abandono escolar temprano (en adelante, AET), la mejora de la calidad educativa y la reducción de desigualdades territoriales como una de las principales preocupaciones de la política educativa actual (Bayón-Calvo, Corrales-Herrero y Ogando Canabal, 2017).

De ahí que las políticas que se dirigen a combatir el AET son prioritarias en la estrategia política nacional y autonómica. Los estudios que han centrado su atención en el AET han abordado esta problemática social desde diversas teorías explicativas. Rumberger (2004) sintetiza estas en dos perspectivas; por un lado, la perspectiva individual, que centra su atención en las características de la persona y, por otro, la perspectiva institucional, que se ocupa de los factores contextuales. Sin embargo, el fundamento teórico de este artículo se sustenta en aquellos enfoques que integran ambas perspectivas en torno a un modelo ecológico de comprensión del AET (Escudero, 2005), pues se parte de la tesis de que este fenómeno requiere una aproximación multifactorial y poliédrica que lo relaciona con los procesos de inclusión/exclusión social. Al mismo tiempo, al valorar los factores de protección y riesgo de los compromisos documentales de la política nacional y autonómica de lucha contra el AET, este artículo también se asocia a los enfoques de la teoría del cambio (Rambla y Fontdevila, 2015; Tarabini, Currán, Montes y Parcerisa, 2015). Por ello, aunque la 
mayoría de estudios se centran en tratar de explicar la relación entre variables dependientes e independientes, este trabajo centra su atención en escuchar también las experiencias de profesionales vinculados a este fenómeno.

\section{Método}

Esta investigación analiza, desde una perspectiva socioeducativa, los distintos sistemas educativos autonómicos que existen en nuestro país. Para ello, se plantea el logro de los siguientes objetivos específicos: conocer las distancias en los resultados educativos entre las distintas autonomías y la conexión con sus contextos socioeconómicos; profundizar en el perfil sociodemográfico vinculado al fracaso y al abandono escolar; y valorar la respuesta institucional autonómica ofrecida en materia de política educativa.

La estrategia metodológica empleada es mixta, complementando fuentes secundarias (análisis estadístico, revisión de estudios y análisis documental) y primarias (entrevista a profesionales). Esta combinación de técnicas es bastante innovadora, sobre todo en lo relativo al tipo de análisis documental de la política educativa, de la que solo se conoce un precedente (Hernández, 2019). En cuanto a las fuentes secundarias, en la explotación estadística de datos se han empleado indicadores de resultados educativos y de gasto social en educación, tomando como periodo de estudio el comprendido entre 2007 y el 2016. Por su parte, la revisión de estudios recientes se ha centrado en mayor medida en aquellos vinculados con el perfil social del AET y las políticas socioeducativas. Finalmente, el análisis documental se complementa con el estudio del gasto social para el análisis de la respuesta institucional. Los documentos analizados son aquellos que permiten valorar el nivel de compromiso nacional y autonómico con la política socioeducativa. En la selección de documentos, se han considerado aquellos que conforman la política socioeducativa (normativa, planes, programas y ayudas) y el periodo de análisis es de 2007-2016, mientras que para la normativa se ha considerado siempre la más reciente. Se han diferenciado dos niveles de análisis, estatal y autonómico. En ambos se han considerado dos componentes de la política socioeducativa, en gran medida paralelos (AET, fracaso y refuerzo escolar), si bien a nivel nacional se ha incluido normativa de su competencia (LOMCE y becas para el estudio).

En cuanto a las fuentes primarias, se han realizado 16 entrevistas a profesionales que ejercen su actividad laboral en entornos vinculados con la formación y las políticas socioeducativas (10 hombres y 6 mujeres), ya sea través de la investigación, la intervención socioeducativa o el asesoramiento laboral. Todos participantes entrevistados son de la Región de Murcia, por ser la ubicación en la que se desarrolla el estudio, y una de las comunidades que presenta niveles más altos de AET y fracaso escolar a nivel nacional. Al tratarse expertos seleccionados por su alto conocimiento de la realidad desde diferentes ámbitos administrativos y áreas de actuación su opinión es muy significativa, y en gran parte, extrapolable a la del conjunto del Estado. 
Las entrevistas se llevaron a cabo entre junio y septiembre de 2017, siguiendo un guion semiestructurado en 4 bloques: 1) perfil social de jóvenes con abandono o fracaso escolar; 2) causas del abandono o fracaso escolar; 3) relación del abandono o fracaso escolar con otros ámbitos de la exclusión social (ingresos, trabajo, familia, ...) y 4) valoración de la política socioeducativa en España. En la selección de los entrevistados se consideraron dos variables que pueden establecer diferencias en la valoración del perfil social de los jóvenes con éxito o fracaso escolar y también en la opinión sobre las políticas socioeducativas: el área de ejercicio de la profesión y el tipo de institución en la que se realiza. Se han tenido en cuenta distintas instituciones: administración autonómica y local; universidad; tercer sector de acción social; sindicatos; patronal; empresa de economía social; y se han diferenciado las siguientes áreas de ejercicio de actividad profesional: investigación (varios perfiles de educación), servicios de apoyo a la juventud en formación (fracaso escolar, formación para el empleo y emprendimiento) y otras áreas vinculadas (empleo, vivienda, familia, salud-adicciones). La Tabla 1 recoge el perfil profesional de los técnicos entrevistados, cuyo discurso se recoge en el texto indicando su perfil abreviado $(T 1, T 2, \ldots)$.

Tabla 1

Perfil profesional de los 16 técnicos entrevistados.

\begin{tabular}{lll}
\hline Perfil & Institución & Área de conocimiento y/o de ejercicio profesional \\
\hline T1 & Administración Autonómica & Educación/Atención a la diversidad \\
T2 & Administración Local & Educación de Adultos \\
T3 & Universidad & Educación/Organización Escolar \\
T4 & Universidad & Educación/Teoría de la Educación \\
T5 & Universidad & Educación/Organización escolar \\
T6 & Patronal & Empleo y Formación \\
T7 & Administración Autonómica & Empleo y Formación \\
T8 & Administración Local & Empleo y Formación \\
T9 & Universidad & Empleo e Ingresos \\
T10 & Sindicato & Empleo y Formación \\
T11 & Tercer Sector & Empleo y Formación \\
T12 & Empresa de Economía Social & Empleo y Responsabilidad social \\
T13 & Tercer Sector & Empleo/Discapacidad \\
T14 & Tercer Sector & Salud/Adicciones \\
T15 & Administración Local & Vivienda/Participación \\
T16 & Administración Local & Servicios Sociales/Familia \\
\hline
\end{tabular}

Fuente: Elaboración propia.

\section{Resultados}

\subsection{Contextualización territorial de los resultados educativos}

El análisis de la literatura especializada muestra la complejidad para establecer una definición universal y compartida del concepto de fracaso escolar. No obstante, 
las distintas interpretaciones hacen alusión a la imposibilidad o incapacidad de un alumno para alcanzar los objetivos establecidos por el sistema educativo que se traduce, generalmente, en la obtención de calificaciones académicas no satisfactorias que conducen a la no obtención del título en ESO. Si bien la relación fracaso escolar y AET no se manifiesta con claridad en la literatura (Fernández-Enguita, Mena y Rivière, 2010), existen enfoques que identifican el fracaso escolar con el alumnado que abandona la educación obligatoria sin la titulación correspondiente (Escudero, 2005). Por eso, desde estos parámetros, se entiende en este artículo que uno de los indicadores más utilizados para determinar el éxito o fracaso educativo lo constituye la tasa de AET del sistema educativo, entendido como el porcentaje de personas comprendidas entre 18 y 24 años, cuyo nivel máximo de estudios ha alcanzado la primera etapa de la educación secundaria o niveles educativos anteriores y que no siguen ningún tipo de educación o formación.

La tasa de AET en España se sitúa en 2016 en el 19\%, dato muy superior al de la media de la UE-28 (10,7\%), pese al descenso en los últimos años; y aún lejano al objetivo del 15\% marcado en la Estrategia Europea 2020 (Rambla y Fontdevila, 2015; Romero y Hernández, 2019), siendo una tasa con una acusada desigualdad entre las diferentes comunidades autónomas, como se verá más adelante.

Tabla 2

Evolución del riesgo de pobreza o exclusión social (tasa AROPE) según nivel de formación alcanzado (personas de 16 y más años), España, 2008 y 2016.

\begin{tabular}{lccc}
\hline & 2008 & 2016 & TV 2008-2016 (\%) \\
\hline Total & 22,7 & 27,2 & 19,8 \\
Educación primaria o inferior & 32,8 & 31,5 & $-4,0$ \\
Educación secundaria primera etapa & 25,4 & 37,9 & 49,2 \\
Educación secundaria segunda etapa & 18,9 & 26,2 & 38,6 \\
Educación superior & 9,8 & 14,5 & 48,0 \\
No consta & 30,4 & 29,0 & $-4,6$ \\
\hline
\end{tabular}

Fuente: INE, ECV.

Las altas tasas de AET en España implican, en gran medida, que los logros educativos sean bajos. En la Tabla 2 se pone de manifiesto, en los dos años analizados, que los bajos niveles educativos suponen un mayor riesgo de pobreza y exclusión social. Como se observa, cuando se tienen estudios superiores a secundarios de segunda etapa el riesgo desciende, siendo un claro factor de protección para aquellos que alcanzan estudios superiores. No obstante, la variación en el periodo es muy alta para todos los niveles, exceptuando los niveles educativos más bajos. Sin duda, este hecho se relaciona con la demanda de trabajo no cualificado y precario a partir de la crisis, afectando en menor medida a los niveles educativos más bajos.

Teniendo en cuenta la perspectiva territorial, en la Tabla 3 se incluyen dos indicadores educativos, encontrando en ambos grandes distancias entre autonomías y una mejora considerable en el periodo 2007-2016. Respecto al AET, en todas las 
comunidades autónomas se aprecia un descenso durante la última década, al tiempo que se reducen las distancias entre ellas. País Vasco ostenta unos niveles más altos, es decir, las tasas más bajas en ambos años, reduciéndose en 2016 hasta el 7,9\%. Por otro lado, los niveles más bajos o tasas más altas en 2007 se encuentran en Ceuta, Melilla y Baleares, con valores superiores al 40\%. En 2016 los niveles más altos están de nuevo en Baleares y Melilla, a las que se suma Murcia con $26,8 \%$. Se debe observar que Cantabria presenta el mayor descenso porcentual en el periodo, $66,2 \%$, lo que la ubica en el segundo puesto en 2016.

Tabla 3

Evolución de indicadores educativos en España, 2007 y 2016 y tasa de variación (\%).

\begin{tabular}{|c|c|c|c|c|c|c|c|}
\hline \multicolumn{4}{|c|}{ Tasa de abandono escolar temprano (18-24 años) } & \multicolumn{4}{|c|}{$\begin{array}{c}\text { Población de } 25-64 \text { años que ha completado } \\
\text { estudios postobligatorios }\end{array}$} \\
\hline Autonomía & 2007 & 2016 & TV (\%) & Autonomía & 2007 & 2016 & TV (\%) \\
\hline País Vasco & 14,3 & 7,9 & $-44,7$ & Madrid & 65,3 & 71,1 & 8,9 \\
\hline Cantabria & 25,5 & 8,6 & $-66,2$ & País Vasco & 62,9 & 70,5 & 12,0 \\
\hline Navarra & 16,3 & 13,4 & $-17,7$ & Navarra & 59,0 & 67,9 & 15,1 \\
\hline Madrid & 25,8 & 14,6 & $-43,4$ & Asturias & 51,2 & 64,3 & 25,7 \\
\hline Galicia & 23,5 & 15,2 & $-35,3$ & Aragón & 55,5 & 63,7 & 14,8 \\
\hline Asturias & 23,1 & 16,6 & $-28,1$ & Cantabria & 53,8 & 63,5 & 18,0 \\
\hline Castilla y León & 23,7 & 17,3 & $-27,0$ & Cataluña & 52,6 & 60,4 & 14,8 \\
\hline La Rioja & 30,6 & 17,8 & $-41,8$ & La Rioja & 54,1 & 60,3 & 11,4 \\
\hline Cataluña & 31,2 & 18,0 & $-42,3$ & España & 50,7 & 58,3 & 15,0 \\
\hline Canarias & 36,4 & 18,9 & $-48,0$ & Castilla y León & 50,8 & 58,1 & 14,4 \\
\hline España & 30,8 & 19,0 & $-38,3$ & Islas Baleares & 45,5 & 57,7 & 27,0 \\
\hline Aragón & 25,5 & 19,1 & $-25,0$ & C. Valenciana & 48,3 & 56,7 & 17,4 \\
\hline C. Valenciana & 31,2 & 20,2 & $-35,2$ & Galicia & 46,9 & 56,5 & 20,4 \\
\hline Extremadura & 34,4 & 20,4 & $-40,6$ & Canarias & 46,4 & 53,9 & 16,1 \\
\hline Andalucía & 37,1 & 23,1 & $-37,7$ & Región de Murcia & 44,4 & 50,1 & 12,8 \\
\hline Castilla-La Mancha & 37,3 & 23,2 & $-37,8$ & Andalucía & 41,8 & 49,2 & 17,8 \\
\hline Región de Murcia & 39,2 & 26,4 & $-32,6$ & Castilla-La Mancha & 41,3 & 49,1 & 18,9 \\
\hline Islas Baleares & 42,1 & 26,8 & $-36,3$ & Extremadura & 37,3 & 42,2 & 13,1 \\
\hline Distancia autonómica & 34,8 & 13,4 & $-61,5$ & Distancia autonómica & 28,0 & 28,9 & 3,3 \\
\hline
\end{tabular}

Fuente: Eurostat (Population and social conditions. Youth. Youth education and training). 
En cuanto al segundo indicador incluido en la Tabla 3, porcentaje de población de 25-64 años con estudios postobligatorios, como era de esperar, la posición de las autonomías es bastante similar al indicador anterior. Además, se trata también de un indicador que ha mejorado bastante en el periodo en todas las regiones, si bien, la distancia entre los primeros y últimos puestos ha aumentado levemente (3\%), situándose en 2016 en 28,9 puntos porcentuales.

La Tabla 4 incluye otros dos indicadores que nos informan de la eficacia y eficiencia del sistema educativo por autonomías. El primero de ellos, la tasa neta de escolarización a los 17 años nos informa sobre la continuidad de los estudios postobligatorios. La evolución y las posiciones son muy similares, como era de esperar a las de la tasa de AET. La evolución de este indicador es favorable en todas las autonomías, aunque en unas más que otras y las distancias autonómicas se reducen, siendo aún importantes en 2016 (18,2 puntos porcentuales). Así, País Vasco y Navarra ocupan los primeros puestos mientras Canarias y Baleares se sitúan en los últimos. Destaca el importante avance en Baleares, no impidiendo que ocupe el último lugar en este ranking.

Tabla 4

Evolución de indicadores de resultados del sistema educativo, cursos 2007-08 y 2015-16.

\begin{tabular}{|c|c|c|c|c|c|c|c|}
\hline \multicolumn{4}{|c|}{ Tasa neta de escolarización a los 17 años } & \multicolumn{4}{|c|}{ Tasa de idoneidad a los 12 años } \\
\hline Autonomía & 2007-08 & $2015-16$ & TV (\%) & Autonomía & 2007-08 & $2015-16$ & TV (\%) \\
\hline País Vasco & 93,0 & 97,9 & 5,3 & Cataluña & 90,4 & 92,4 & 2,2 \\
\hline Navarra & 79,4 & 94,2 & 18,6 & La Rioja & 86,1 & 88,9 & 3,3 \\
\hline Castilla y León & 86,6 & 93,9 & 8,4 & Cantabria & 83,4 & 87,9 & 5,4 \\
\hline Galicia & 79,2 & 93,5 & 18,1 & País Vasco & 87,6 & 87,8 & 0,2 \\
\hline La Rioja & 75,5 & 93,3 & 23,6 & Asturias & 81,5 & 87,7 & 7,6 \\
\hline Cantabria & 83,1 & 93,1 & 12,0 & Galicia & 84,0 & 87,5 & 4,2 \\
\hline Madrid & 76,1 & 92,5 & 21,6 & Navarra & 84,0 & 86,4 & 2,9 \\
\hline Asturias & 85,3 & 91,6 & 7,4 & Andalucía & 82,1 & 86,3 & 5,1 \\
\hline Aragón & 79,4 & 91,0 & 14,6 & España & 83,6 & 86,1 & 3,0 \\
\hline Extremadura & 76,0 & 89,7 & 18,0 & Madrid & 83,2 & 85,8 & 3,1 \\
\hline España & 75,0 & 89,4 & 19,2 & Extremadura & 82,7 & 85,5 & 3,4 \\
\hline Cataluña & 73,4 & 88,4 & 20,4 & Castilla y León & 82,4 & 84,8 & 2,9 \\
\hline C. Valenciana & 69,6 & 88,0 & 26,4 & Canarias & 77,3 & 83,2 & 7,6 \\
\hline Región de Murcia & 73,9 & 87,8 & 18,8 & Castilla-La Mancha & 79,0 & 82,6 & 4,6 \\
\hline Andalucía & 72,1 & 87,3 & 21,1 & C. Valenciana & 85,8 & 82,2 & $-4,2$ \\
\hline Castilla-La Mancha & 72,1 & 87,1 & 20,8 & Aragón & 82,2 & 81,8 & $-0,5$ \\
\hline Canarias & 71,8 & 85,7 & 19,4 & Región de Murcia & 77,1 & 81,8 & 6,1 \\
\hline Islas Baleares & 61,1 & 79,7 & 30,4 & Islas Baleares & 75,7 & 80,8 & 6,7 \\
\hline Distancia autonómica & 31,9 & 18,2 & $-42,9$ & Distancia autonómica & 14,7 & 11,6 & $-21,1$ \\
\hline
\end{tabular}

Fuente: Ministerio de Educación y Cultura. Estadísticas de Educación. 
Otro indicador de la eficacia del sistema es la ausencia de fracaso escolar o repetición de curso, que se puede medir a partir de la idoneidad a los 12 años. En este caso la posición se ve alterada con relación al indicador anterior. Es el caso de algunas que ocupan, ahora, puestos intermedios, mientras tenían resultados más bajos en indicadores anteriores, como Extremadura o Andalucía; y otras, como Madrid o Navarra, también en puestos intermedios ahora $y$, anteriormente, en mejores posiciones. No obstante, los resultados más bajos los ostentan en 2016 Baleares y Murcia; se trata, de nuevo, de un indicador con evolución positiva en todas las autonomías, exceptuando la Comunidad Valenciana, a la vez que se ven reducidas las distancias entre resultados.

Tabla 5

Resultados de Informe PISA de la OCDE por tipo de competencia y autonomía, 2009 y 2015, orden descendente 2015 Habilidad lectora.

\begin{tabular}{|c|c|c|c|c|c|c|c|c|c|}
\hline \multirow{2}{*}{ Autonomía } & \multicolumn{3}{|c|}{ Habilidad lectora } & \multicolumn{3}{|c|}{ Matemáticas } & \multicolumn{3}{|c|}{ Ciencias } \\
\hline & 2009 & 2015 & Variación & 2009 & 2015 & Variación & 2009 & 2015 & Variación \\
\hline Castilla y León & 503 & 522 & 19 & 514 & 506 & -8 & 516 & 519 & 3 \\
\hline Madrid & 503 & 520 & 17 & 496 & 503 & 7 & 508 & 516 & 8 \\
\hline Navarra & 497 & 514 & 17 & 511 & 518 & 7 & 509 & 512 & 3 \\
\hline Galicia & 486 & 509 & 23 & 488 & 494 & 6 & 506 & 512 & 6 \\
\hline Aragón & 495 & 506 & 11 & 506 & 500 & -6 & 505 & 508 & 3 \\
\hline Cantabria & 488 & 501 & 13 & 495 & 495 & 0 & 500 & 496 & -4 \\
\hline Cataluña & 498 & 500 & 2 & 496 & 500 & 4 & 497 & 504 & 7 \\
\hline C. Valenciana & 477 & 499 & 22 & 487 & 485 & -2 & 486 & 494 & 8 \\
\hline Castilla-La Mancha & 470 & 499 & 29 & 483 & 486 & 3 & 481 & 497 & 16 \\
\hline Asturias & 490 & 498 & 8 & 494 & 492 & -2 & 502 & 501 & -1 \\
\hline España & 481 & 496 & 15 & 483 & 486 & 3 & 488 & 493 & 5 \\
\hline Media OCDE & 493 & 493 & 0 & 496 & 492 & -4 & 501 & 493 & -8 \\
\hline La Rioja & 498 & 491 & -7 & 504 & 505 & 1 & 509 & 498 & -11 \\
\hline País Vasco & 494 & 491 & -3 & 510 & 492 & -18 & 495 & 483 & -8 \\
\hline Región de Murcia & 480 & 486 & 6 & 478 & 470 & -8 & 484 & 484 & 0 \\
\hline Islas Baleares & 457 & 485 & 28 & 464 & 476 & 12 & 461 & 485 & 24 \\
\hline Canarias & 448 & 483 & 35 & 435 & 452 & 17 & 452 & 475 & 23 \\
\hline Andalucía & 461 & 479 & 18 & 462 & 466 & 4 & 469 & 473 & 4 \\
\hline Extremadura & 459 & 475 & 16 & 478 & 473 & -5 & 479 & 474 & -5 \\
\hline Distancia autonómica & 46 & 47 & 1 & 79 & 33 & -46 & 64 & 45 & -19 \\
\hline
\end{tabular}

Fuente: OCDE.

Los resultados del Informe PISA que elabora la OCDE también son un buen indicador de la eficacia del sistema educativo autonómico. Este informe se compone de tres competencias diferenciadas, siendo los datos disponibles para analizar su evolución de 2009 y 2015. Como se observa en la Tabla 5, los valores entre ellas son muy similares y las distancias autonómicas son patentes en las tres pruebas que se 
realizan, tendiendo a la estabilidad en habilidad lectora, aunque se reducen en las otras dos.

Tabla 6

Evolución de indicadores de gestión del sistema educativo, cursos 2007-08 y 2015-16.

\begin{tabular}{|c|c|c|c|c|c|c|c|}
\hline \multicolumn{4}{|c|}{ \% Alumnado en enseñanza pública } & \multicolumn{4}{|c|}{$\mathrm{N}^{\circ}$ medio alumnos / unidad en E. Primaria } \\
\hline Autonomía & 2007-08 & $2015-16$ & TV (\%) & Autonomía & 2007-08 & $2015-16$ & TV (\%) \\
\hline Castilla-La Mancha & 82,5 & 81,4 & $-1,3$ & Extremadura & 17,8 & 18,3 & 2,8 \\
\hline Extremadura & 79,0 & 80,3 & 1,6 & Castilla y León & 17,4 & 18,6 & 6,9 \\
\hline Canarias & 77,3 & 76,5 & $-1,0$ & Galicia & 17,7 & 19,6 & 10,7 \\
\hline Andalucía & 75,6 & 74,8 & $-1,1$ & Asturias & 18,4 & 19,9 & 8,2 \\
\hline Galicia & 71,7 & 72,8 & 1,5 & Aragón & 19,2 & 19,9 & 3,6 \\
\hline Asturias & 69,4 & 71,7 & 3,3 & Navarra & 19,3 & 20,1 & 4,1 \\
\hline Región de Murcia & 73,0 & 71,0 & $-2,7$ & Castilla-La Mancha & 19,2 & 20,2 & 5,2 \\
\hline Cantabria & 65,9 & 70,4 & 6,8 & Cantabria & 17,5 & 20,7 & 18,3 \\
\hline Aragón & 65,2 & 68,4 & 4,9 & País Vasco & 19,9 & 21,5 & 8,0 \\
\hline Castilla y León & 67,1 & 68,2 & 1,6 & La Rioja & 21,8 & 21,7 & $-0,5$ \\
\hline España & 67,3 & 67,8 & 0,7 & Canarias & 21,3 & 21,8 & 2,3 \\
\hline C. Valenciana & 68,3 & 66,5 & $-2,6$ & España & 21,0 & 21,9 & 4,3 \\
\hline La Rioja & 66,6 & 66,4 & $-0,3$ & Andalucía & 21,9 & 22,2 & 1,4 \\
\hline Cataluña & 62,1 & 65,8 & 6,0 & Región de Murcia & 22,3 & 22,4 & 0,4 \\
\hline Islas Baleares & 64,1 & 64,7 & 0,9 & C. Valenciana & 21,4 & 22,6 & 5,6 \\
\hline Navarra & 65,4 & 64,5 & $-1,4$ & Cataluña & 22,8 & 22,9 & 0,4 \\
\hline Madrid & 53,6 & 54,8 & 2,2 & Islas Baleares & 23,1 & 23,0 & $-0,4$ \\
\hline País Vasco & 49,3 & 50,9 & 3,2 & Madrid & 22,8 & 23,7 & 3,9 \\
\hline Distancia autonómica & 33,2 & 30,5 & $-8,1$ & Distancia autonómica & 5,7 & 5,4 & $-5,3$ \\
\hline
\end{tabular}

Fuente: Ministerio de Educación y Cultura. Estadísticas de Educación.

Continuando con los indicadores del sistema educativo y su situación autonómica, en la Tabla 6 se han incluido los que se refieren a la gestión, en concreto, la distribución del alumnado en centros públicos/privados y el número medio de alumnos por unidad en Educación Primaria. Como se observa, la gestión de la educación varía enormemente de unas comunidades a otras en cuanto a la titularidad pública/privada de los centros, produciéndose cierto acercamiento, con tendencia al aumento de la enseñanza pública. La escasa variación que se observa entre los dos cursos analizados (2007-08 y 2015-16) hace pensar que se trata de modelos educativos consolidados. Mientras algunas autonomías abogan por una mayor titularidad de centros públicos, como Castilla-La Mancha, Extremadura, Murcia o Andalucía, con una participación privada inferior al 30\%; otras autonomías presentan un sistema bastante equilibrado entre participación privada y pública, como País Vasco y Madrid, curiosamente las que vimos anteriormente que presentaban mejores resultados. 
Otro indicador que nos informa sobre el modelo de gestión educativa es el que se relaciona con los recursos profesionales, en particular, con el número de alumnos por aula en Educación Primaria (Tabla 6). La evolución de este indicador describe un aumento casi generalizado de esta ratio en el periodo analizado, sin duda, vinculado con los efectos de la crisis en los presupuestos públicos. Las distancias entre autonomías se reducen levemente, aunque siguen por encima de cinco estudiantes. Sin embargo, la mayor o menor densidad de alumnos en aula de Educación Infantil no guarda siempre una relación directa con los resultados vistos anteriormente en AET; así Extremadura es la que tiene menor ratio (18,3 alumnos/profesor) y ofrecía la mayor tasa AET, al tiempo que Madrid es la de mayor ratio $(23,7)$ y su tasa era muy baja. No obstante, para otras autonomías, como Baleares o Murcia, queda patente la relación positiva entre menos profesorado y mayor AET.

Con ánimo de encontrar explicaciones a las distancias autonómicas en los niveles educativos y en particular en el AET, se han considerado varios indicadores demográficos, como el porcentaje de jóvenes, la ruralidad o el peso de la población extranjera, si bien ninguno de ellos guardaba relación clara con los niveles educativos vistos o el abandono educativo. Sin embargo, sí se ha encontrado vinculación con otros indicadores socioeconómicos contemplados e incluidos en la Tabla 7 (tasa AROPE y PIB per cápita) que ofrecen una importante correlación con los niveles educativos de la población adulta y con el AET en gran número de autonomías.

Tabla 7

Evolución de indicadores de contexto económico, 2007-2016.

\begin{tabular}{lccc|lccc}
\hline \multirow{2}{*}{ Autonomía } & \multicolumn{3}{c|}{ Tasa AROPE (\%) } & \multicolumn{3}{c}{ PIB per cápita $(€)$} \\
& 2008 & 2016 & TV $(\%)$ & & 2007 & 2016 & TV $(\%)$ \\
\hline Navarra & 8,6 & 13,0 & 51,2 & Madrid & 31.617 & 32.815 & 3,8 \\
País Vasco & 13,9 & 15,9 & 14,4 & País Vasco & 30.259 & 31.784 & 5,0 \\
La Rioja & 19,6 & 17,4 & $-11,2$ & Navarra & 29.451 & 30.006 & 1,9 \\
Cataluña & 15,6 & 17,9 & 14,7 & Cataluña & 28.124 & 28.825 & 2,5 \\
Asturias & 19,5 & 18,5 & $-5,1$ & Aragón & 26.141 & 26.097 & $-0,2$ \\
Aragón & 17,1 & 18,7 & 9,4 & La Rioja & 25.492 & 25.317 & $-0,7$ \\
Islas Baleares & 23,6 & 19,1 & $-19,1$ & Islas Baleares & 25.502 & 25.063 & $-1,7$ \\
Madrid & 19,3 & 21,7 & 12,4 & España & 23.893 & 24.080 & 0,8 \\
Castilla y León & 21,4 & 23,2 & 8,4 & Castilla y León & 22.082 & 22.723 & 2,9 \\
Cantabria & 19,9 & 24,6 & 23,6 & Cantabria & 22.436 & 21.574 & $-3,8$ \\
Galicia & 25,1 & 25,4 & 1,2 & Galicia & 20.470 & 21.542 & 5,2 \\
España & 23,8 & 27,9 & 17,2 & C. Valenciana & 21.610 & 21.232 & $-1,7$ \\
C. Valenciana & 27,5 & 30,5 & 10,9 & Asturias & 21.759 & 20.855 & $-4,2$ \\
Región de Murcia & 27,5 & 34,8 & 26,5 & Región de Murcia & 19.923 & 19.865 & $-0,3$ \\
Extremadura & 37,9 & 35,8 & $-5,5$ & Canarias & 21.167 & 19.821 & $-6,4$ \\
Castilla-La Mancha & 28,8 & 37,9 & 31,6 & Castilla-La Mancha & 19.322 & 18.849 & $-2,4$ \\
Andalucía & 31,6 & 41,7 & 32,0 & Andalucía & 18.459 & 17.790 & $-3,6$
\end{tabular}


Desigualdades educativas y respuesta institucional: Una investigación desde la perspectiva territorial

\begin{tabular}{lrrr|lllll} 
Canarias & 34,8 & 44,6 & 28,2 & Extremadura & 16.102 & 16.558 & 2,8 \\
\hline Distancia autonómica & 29,3 & 31,6 & 7,8 & Distancia autonómica & 15.515 & 16.257 & 4,8
\end{tabular}

Fuente: INE, Encuesta de Condiciones de Vida (2008 y 2016) y Contabilidad Nacional (2007 y 2016).

Respecto a la tasa AROPE o de riesgo de pobreza y exclusión, se trata de un indicador que ha aumentado de 2008 a 2016 debido a la crisis en todas las autonomías, excepto Rioja, Extremadura y Baleares, y con una distancia elevada aún en 2016 (31,6 puntos), aumentando levemente. En ambos años, los mejores niveles (los más bajos), los presentan Navarra y País Vasco, que a su vez presentaban bajos niveles de AET. Asimismo, autonomías con alto riesgo de exclusión, como Andalucía, Castilla-La Mancha o Extremadura, presentaban altos niveles de abandono. No obstante, se encuentra autonomías donde no hay correspondencia, como es Canarias, que, a pesar de su alta tasa de exclusión, presenta valores medios de AET.

Si consideramos el PIB per cápita obtenemos posiciones muy similares y una evolución inversa, pues la mayoría de las autonomías mejoran su situación, no todas, aunque ahora las distancias se amplían. En los primeros puestos siguen País Vasco y Navarra, aunque la autonomía con mayor PIB per cápita en ambos años es Madrid. Merece la pena resaltar las grandes distancias entre los primeros y últimos puestos. Así, en 2016, Madrid duplica el valor de Extremadura. Respecto a la correlación entre este indicador y el AET, ahora es más clara que en la tasa AROPE, pudiendo explicarse por el diferente periodo contemplado, ya que no se cuenta con la tasa AROPE de 2007. Sin duda otros factores intervienen en la eficacia de los modelos educativos regionales, entre ellos los derivados de la política regional, expresada mediante el nivel de gasto social o la normativa autonómica existente, aspecto que se verán posteriormente.

\subsection{Variables sociodemográficas vinculadas al abandono escolar temprano}

La mayor parte de los estudios sobre AET realizados en España indican que no existe un patrón claro de quien abandona y quien fracasa (Felgueroso, GutiérrezDomènech y Jiménez, 2011; Serrano, Soler, Hernández y Sabater, 2013). La heterogeneidad y diversidad de factores personales, sociales, económicos y escolares es tan grande que hace imposible el poder definir un perfil, más o menos típico, de alumno/a que fracasa y/o abandona. Sin embargo, en el estudio de Fernández-Enguita, Mena y Riviere (2010) se hace el intento de presentar como perfil más repetido de alumnado con fracaso escolar el siguiente: varón, de 15 años, de origen inmigrante, que estudia en un centro público y que es hijo de un trabajador no cualificado. Pero lo cierto es que el perfil de los jóvenes que presentan fracaso y AET es mucho más complejo que esta mera descripción y requiere de un análisis más riguroso. Para ello nos apoyaremos, tanto en datos estadísticos obtenidos de fuentes primarias, como en la consulta de estudios e investigaciones que hayan abordado previamente este asunto y lo acompañaremos de los discursos extraídos de nuestros entrevistados. 
Desigualdades educativas y respuesta institucional: Una investigación desde la perspectiva territorial

Tabla 8

Variables y categorías sociodemográficas asociadas al abandono escolar temprano.

\begin{tabular}{ll}
\hline Variable & Categoría \\
\hline Edad & Intervalo 13-17 años \\
\hline Sexo & $\begin{array}{l}\text { Hombre } \\
\text { Mujer }\end{array}$ \\
\hline Nacionalidad & $\begin{array}{l}\text { Autóctono } \\
\text { Extranjero }\end{array}$ \\
\hline Familia de origen & $\begin{array}{l}\text { Nivel de estudios padres } \\
\text { Renta familiar /Clase social }\end{array}$ \\
\hline \multirow{3}{*}{ Hábitat } & Ciudad \\
& Pueblo \\
& Rural \\
\hline \multirow{2}{*}{ Diversidad funcional } & $\begin{array}{l}\text { Limitación en actividades básicas } \\
\text { Sin limitación en actividades básicas }\end{array}$ \\
\hline
\end{tabular}

Fuente: Elaboración propia.

En la Tabla 8 se recogen las principales variables sociodemográficas asociadas al AET. Cada una de ellas se ha analizado, a través de los datos estadísticos de otros estudios, siendo complementadas con la opinión de los profesionales entrevistados.

En el estudio realizado mediante encuesta, García, Casal, Merino y Sánchez (2013) demuestran que el AET está relacionado con una edad anterior a la utilizada por el indicador de AET, pues seis de cada diez jóvenes abandonan en el último curso de la ESO. La moda la constituyen los 15 años (44\%) y el $20 \%$ del abandono sin graduación se produce a la edad de 14 años. Además, el 7\% de los jóvenes de la encuesta abandonan con 17 años cumplidos; y dos de cada diez jóvenes abandonan la escolarización antes de los 15 años.

Uno de los perfiles sería ese alumnado que llega con quince años a tercero de la ESO y que no tiene titulación. (...) Es un curso, en el que suele haber bastante abandono escolar, (...) ha promocionado por edad (...) ha hecho dos repeticiones (...) el alumno sabe que, por mucho que haga, no va a tener un título de secundaria, se desmotiva, y abandona (T2, Administración. Local, Educación de Adultos).

Entre los factores que se refieren a características individuales del alumnado, el sexo también presenta efectos en la probabilidad de querer abandonar los estudios obligatorios (Mora, 2010). En todos los países de la UE-28, el AET es menor en las mujeres. Aunque en la media de la UE-28 la diferencia es poco significativa (3 puntos), sin embargo, en el contexto español sí lo es (7,6 puntos). Este hecho acentúa la importancia de llevar a cabo el análisis por separado entre hombres y mujeres (Felgueroso, Gutiérrez-Domènech y Jiménez, 2011); pues sin duda factores socioculturales están incidiendo en las diferencias. 
El perfil de jóvenes en mayor riesgo de exclusión social o con graves dificultades sociales viene dado fundamentalmente es un perfil masculino, no doblando, pero casi los hombres a las mujeres en estas situaciones, que no termina los estudios obligatorios, es decir no obtiene el certificado de la ESO o que, habiéndolo obtenido, no continua estudios posteriores (T11, Tercer Sector, Empleo y formación).

Se observan también claras diferencias según la nacionalidad del estudiante. La población de origen extranjero de la UE-28 y de España presenta una tasa de AET notablemente superior en relación con la población de origen autóctono. De hecho, esta tasa, tanto para la UE-28 como para España, se sitúa por encima del doble en comparación con la tasa de la población de origen autóctono. En 2016, mientras la tasa de abandono es del 16,4\% para los españoles, se eleva hasta el 37,6\% en el caso de los extranjeros. Como resultado, aunque los extranjeros suponen solo el $15,2 \%$ de la población de 18 a 24 años, su peso en el total de abandonos supera actualmente el $27 \%$, el máximo del periodo considerado. Por tanto, el alumnado inmigrante muestra una predisposición superior a abandonar sus estudios que el alumnado autóctono (Mora, 2010).

No hemos sabido aprovechar y salvar educativamente a los alumnos inmigrantes y este es un tema que entraña mucho riesgo para el futuro, sólo tenemos que ver lo que está ocurriendo en Francia, Bélgica (...) estamos generando bolsas de exclusión (T2, Administración. Local, Educación de Adultos).

Las características de la familia también permiten apreciar patrones diferenciados de abandono. En este sentido, con respecto al capital cultural de origen, hemos considerado la variable nivel de estudios del padre y de la madre proporcionada por la Encuesta de Población Activa (EPA). Para los jóvenes con padres que carecen de estudios postobligatorios la tasa de abandono casi alcanza el $50 \%$. No obstante, como reflejan los datos, también se dan algunas situaciones de abandono prematuro entre las familias con un capital cultural medio y alto. Por tanto, a mayor nivel de estudios de la madre o del padre, menor probabilidad de que el hijo o hija se encuentre en situación de AET.

Cuando hablamos de alumnado que está en riesgo (...) familias de escasos recursos, con padres que tampoco tienen un alto nivel formativo, con dificultades laborales (...) confluyen una serie de rasgos que, en algún punto de su vida, hacen que abandonen el sistema educativo (T3, Universidad, Educación/Organización Escolar).

La renta familiar también es una variable que influye significativamente en las tasas de AET. A mayor renta familiar, menor probabilidad de que el hijo o la hija deje los estudios. Sin embargo, la estadística de referencia para los datos de abandono, la EPA no ofrece datos acerca de niveles de renta y, por tanto, no permite analizar la relación entre abandono y renta. Para estudiar ese tipo de cuestiones es preciso emplear fuentes estadísticas alternativas, como la Encuesta de Condiciones de Vida (ECV), que contengan la información necesaria sobre niveles educativos e ingresos de los individuos. 
Para un chico que sus padres no tienen trabajo, que viven en una situación de precariedad familiar tremenda, que necesitan el dinero, estos colectivos pues son digamos más vulnerables para que se produzca ese abandono escolar, (...) el porcentaje puede ser el doble o el triple del alumnado (T2, Administración Local, Educación de Adultos).

El tipo de hábitat y el grado de urbanización son otras variables que también tiene su influencia en el AET. Como muestran los datos estadísticos de Eurostat, tanto en la UE-28 como en España, para 2016 los jóvenes de 18-24 años que viven en zonas rurales (20\%) tienen más probabilidades de abandonar que los jóvenes que viven en las ciudades $(15,8 \%)$. Pero más que en el hábitat (pueblo o ciudad) las mayores diferencias se encuentran en las familias que viven en barrios suburbiales o marginales.

Hay muchas zonas donde aparece esa dinámica de bolsas de pobreza, barrios que tienen una marca de identidad que agrupa un sector de población con graves carencias, con población muy vulnerable, etc. $Y$ en esos barrios, habitualmente, suele haber más tasa de abandono y de fracaso que en otras zonas con otro tipo de población distinta (T1, Administración. Autonómica, Educación/Atención a la diversidad).

De igual manera la diversidad funcional o la distinta situación de discapacidad de la persona también es una variable que influye significativamente en el AET. Según datos de Eurostat, los jóvenes de 18-24 años con discapacidad tienen el doble de probabilidad de abandonar tempranamente el sistema educativo que los jóvenes sin discapacidad.

No obstante, además de las variables indicadas, en opinión de Mora (2010) y González (2017), existen otros factores extremadamente decisivos para explicar el abandono como son: el rendimiento escolar del alumnado, el nivel cognitivo, la personalidad del alumno, su estado de salud, la lengua y el centro escolar donde se cursan estudios secundarios.

\subsection{Respuesta institucional para mejorar los resultados educativos}

La estructura territorial en comunidades autónomas del Estado español provoca políticas de descentralización y autonomía en cada territorio que merecen análisis exhaustivos para conocer la respuesta autonómica a un mismo fenómeno educativo. Por consiguiente, en este apartado se realiza un análisis documental de las normativas y desarrollos legislativos con los que cuenta cada comunidad autónoma en materia de AET. En este sentido, se indican las bases documentales de la política socioeducativa del Estado y las propias de cada autonomía. Este análisis es acompañado por las opiniones de los profesionales entrevistados en este estudio.

Además, uno de los factores influyentes que se ha considerado para la búsqueda de una explicación comparada de los índices de AET, ha sido el gasto público en educación realizado por cada comunidad autónoma en la última década. El análisis de este factor se centra, pues, en la evolución de dos índices: el gasto público por alumno en la enseñanza no universitaria y el gasto en educación con relación al PIB de España. 


\subsubsection{Análisis documental de la política socioeducativa estatal}

Con relación a los compromisos legislativos de España en materia de AET, en la Tabla 9 se incluye la documentación en la que se sustenta su política socioeducativa, incluyendo sus componentes: la legislación educativa básica (LOMCE) y todo el conjunto de planes y normas que la refuerzan.

Tabla 9

Bases documentales de la política socioeducativa en España.

\begin{tabular}{llc}
\hline Componente & \multicolumn{1}{c}{ Documento (Normativa, plan, programa) } & Año/Periodo \\
\hline Normativa básica & LOMCE & 2013 \\
Becas al estudio & Sistema de Becas y ayudas al estudio & anual, 2016 \\
Educación para adultos & Plan estratégico de aprendizaje a lo largo de toda la vida & 2015 \\
Abandono escolar & $\begin{array}{l}\text { Plan estratégico para la reducción del abandono educativo } \\
\text { temprano }\end{array}$ & $2014-2020$ \\
Fracaso y refuerzo escolar & Plan nacional PROA & anual, 2016 \\
\hline
\end{tabular}

Fuente: Elaboración propia.

En relación con la Ley Orgánica 8/2013, de 9 de diciembre, para la mejora de la calidad educativa o LOMCE, entre sus objetivos de acción prioritaria, se encuentra el de reducir la tasa de AET y flexibilizar el sistema y las trayectorias curriculares para evitar la exclusión del alumnado. Sin embargo, algunos profesionales se muestran muy críticos con la sustitución de los Programas de Cualificación Inicial (PCPI), por los ciclos iniciales de Formación Profesional Básica (FP Básica).

La LOMCE es segregadora, además segrega tempranamente. Al final son carne de cañón para la FP básica, que ha sido la sustitución de un programa que funcionaba muy bien, que eran los programas de cualificación inicial profesional, con el objetivo, únicamente, de maquillar las cifras de abandono escolar (T10, SindicatoEmpleo y Formación).

En la educación formal deberían meter algunas horas de habilidades sociales y pre laboral, que conozcan una nómina que sepan los salarios, que conozcan un convenio (...) que conozcan sus derechos y obligaciones como trabajadores (...) valores y orientación laboral que es fundamental (T11, Tercer Sector-Empleo y Formación).

Otra de las críticas hacia este currículo es no incluir valores de sensibilización y concienciación hacia diversos temas como la pobreza y el conocimiento de la existencia de las ayudas sociales que puedan necesitar en un futuro.

Concienciación, que sepan que prestaciones pueden pedir y después qué tipo de ayudas pueden tener en otro tipo de asociaciones y tercer sector (...) hay que trabajarlo desde el colegio, ese aspecto de sensibilizar y concienciar, en eso de la vergüenza (...) dedicar más horas a los valores, a habilidades sociales, a la igualdad (T1, Administración Autonómica-Educación/Atención a la Diversidad). 
En cuanto al Sistema de Becas y ayudas al estudio podemos decir que su principal objetivo es compensar las desigualdades económicas que puedan impedir el acceso a alumnado en riesgo de exclusión social con el fin de garantizar la igualdad de oportunidades, intentando romper la relación existente entre AET y nivel económico familiar. Dentro de este sistema de becas, se observa que entre 2008 y 2015 aumenta el importe y la proporción de estas para la enseñanza postobligatoria, al contrario que las enseñanzas obligatoria, infantil y especial. No obstante, desde el año 2013 se han eliminado becas y modificado los requisitos para acceder a ellas, además de calcularse en base a una parte fija y otra variable.

En el conjunto del Estado hemos tenido un recorte de 9000 millones de inversión educativa, hemos tenido un agravamiento del gasto familiar en más de 3000 millones de euros de dinero que las familias no tenían que poner y ahora sí, por qué, porque se ha torpedeado la política de becas, de ayudas sociales y otro tipo de medidas de servicios educativos complementarios como los comedores escolares, ayudas de libros... (T11, Tercer Sector-Empleo y Formación).

El Plan estratégico de aprendizaje a lo largo de toda la vida pretende mejorar las habilidades de los individuos, sin limitarse a un tiempo o a una edad concreta y sin definir colectivos beneficiarios concretos con el fin de acercarlos a los objetivos que establece el Marco Estratégico para la cooperación europea en el ámbito de la educación y la formación (ET 2020).

Con relación al Plan estratégico para la reducción del abandono educativo temprano, su objetivo principal es incidir en los factores que afectan al fracaso escolar y facilitar la reincorporación del alumnado que se encuentre en situación de AET. Dentro del plan se incluyen los planes específicos territoriales o institucionales. No obstante, los profesionales matizan que no es suficiente.

Necesitamos itinerarios integrados. Si no trabajamos de una manera integral y transversal, difícilmente podremos conseguir (...) que cada vez menos personas en riesgo de exclusión las que no accedan al mercado laboral (...) Un trabajo multidimensional (...) Si no jugamos todos en un mismo equipo con el mismo objetivo de colar los goles juntos difícilmente vamos a conseguir cambiar la situación (T4, Universidad-Educación/Teoría de la Educación).

Por último, el Plan nacional PROA es un plan dirigido a centros con un alto porcentaje de alumnado en desventaja social. Su objetivo es reducir los factores que provocan la desigualdad y mejora la formación de los colectivos más vulnerables.

Yo creo que es fundamentalmente reforzar todo el sistema educativo... con programas realmente importantes. Departamentos como el de Atención a la Diversidad tendrían que tener más recursos para poder hacer actividades complementarias y poder llevar programas específicos (T1, Administración Autonómica-Educación/Atención a la Diversidad). 


\subsubsection{Análisis documental de la política autonómica socioeducativa}

La política socioeducativa de cada autonomía se complementa con las medidas nacionales anteriores, si bien con distinto compromiso con los colectivos más desfavorecidos o con peores resultados. Aunque existen cuatro componentes autonómicos de la política educativa, se han considerado los vinculados directamente con prevención del abandono y fracaso escolar, no siendo analizados los programas de educación de adultos ni los de atención a la diversidad por cuestiones de espacio.

Como se observa en la Tabla 10, la mayoría de las comunidades autónomas cuentan con un documento específico (plan, decreto, protocolo, orden) que regula la prevención, intervención, control y seguimiento de las situaciones de absentismo o abandono. No obstante, difieren en tres variables importantes que también muestran diferencias entre autonomías de la consideración del fenómeno del AET: a) rango de documento legislativo; b) inclusión de medidas preventivas y/o de intervención; c) inicio de las medidas de actuación. Si bien en el momento de elaboración de este trabajo, Asturias, Baleares, Castilla y León, Madrid, País Vasco y C. Valenciana no disponen de un plan o norma específica sobre el AET, sí cuentan con programas específicos en planes o normas más generales.

Tabla 10

Planes/normas en vigor sobre abandono escolar, según autonomía (caracterización).

\begin{tabular}{|c|c|c|c|c|c|}
\hline Autonomía & $\begin{array}{c}\text { Tipo de } \\
\text { documento }\end{array}$ & Período & $\begin{array}{c}\text { Medidas } \\
\text { contempladas }\end{array}$ & Autonomía & $\begin{array}{l}\text { Niveles educativos } \\
\text { contemplados }\end{array}$ \\
\hline Andalucía & Plan & $2016-2020$ & \multirow{9}{*}{$\begin{array}{l}\text { Prevención y } \\
\text { otras }\end{array}$} & A d d ó & \multirow{5}{*}{$\begin{array}{c}\text { Infantil y otros } \\
\text { niveles }\end{array}$} \\
\hline Aragón & Programa & 2015-act. & & Alluatucia & \\
\hline Región de Murcia & Plan & $2014-16$ & & Extremadura & \\
\hline \multirow{2}{*}{ Galicia } & Protocolo & 2014-act. & & La Rioja & \\
\hline & Decreto & 2011 & & Navarra & \\
\hline Cantabria & Plan & 2013-act. & & Aragón & \multirow{8}{*}{$\begin{array}{l}\text { Otros niveles sin } \\
\text { Infantil }\end{array}$} \\
\hline \multirow{2}{*}{ Castilla-La Mancha } & Plan & $2010-15$ & & R. Murcia & \\
\hline & Orden & $2007^{*}$ & & & \\
\hline Extremadura & Plan & 2007-act. & & Gaticla & \\
\hline Canarias & Resolución & $2016-2017$ & \multirow{4}{*}{$\begin{array}{l}\text { Otras medidas } \\
\text { sin prevención }\end{array}$} & Cantabria & \\
\hline Navarra & Protocolo & 2014-act. & & Cataluña & \\
\hline Cataluña & Plan & $2012-18$ & & Castilla-La Mancha & \\
\hline La Rioja & Decreto & 2009 & & Canarias & \\
\hline
\end{tabular}

Fuente: Elaboración propia.

Nota: En el resto de autonomías no hay: Asturias, Islas Baleares, Castilla y León, Madrid, País Vasco, C. Valenciana. 
En el caso de las comunidades autónomas de Andalucía, Aragón, Región de Murcia, Galicia, Cantabria, Castilla-La Mancha y Extremadura este documento incorpora medidas de prevención e intervención, no obstante, en Canarias, Navarra, Cataluña y La Rioja el documento existente hace referencia, en concreto, a medidas de intervención, no apareciendo reflejado el principio de prevención.

La Tabla 11 muestra los planes y normas autonómicos que hacen referencia al fracaso y refuerzo escolar. A excepción de Asturias, Baleares y Castilla y León el resto de las autonomías cuenta con medidas de refuerzo curricular, si bien se aplican solo en la ESO en algunas (País Vasco, Canarias, Murcia o Navarra). Tan solo Navarra, Canarias y Galicia plantean medidas que supone un incremento con las actuaciones que se proponen desde el Plan Nacional PROA. En el caso de las autonomías de Asturias y Castilla y León, los programas y medidas dirigidas a la prevención y actuación contra el fracaso escolar datan del año 2017.

Tabla 11

Planes/normas en vigor sobre fracaso y refuerzo escolar según autonomía (características).

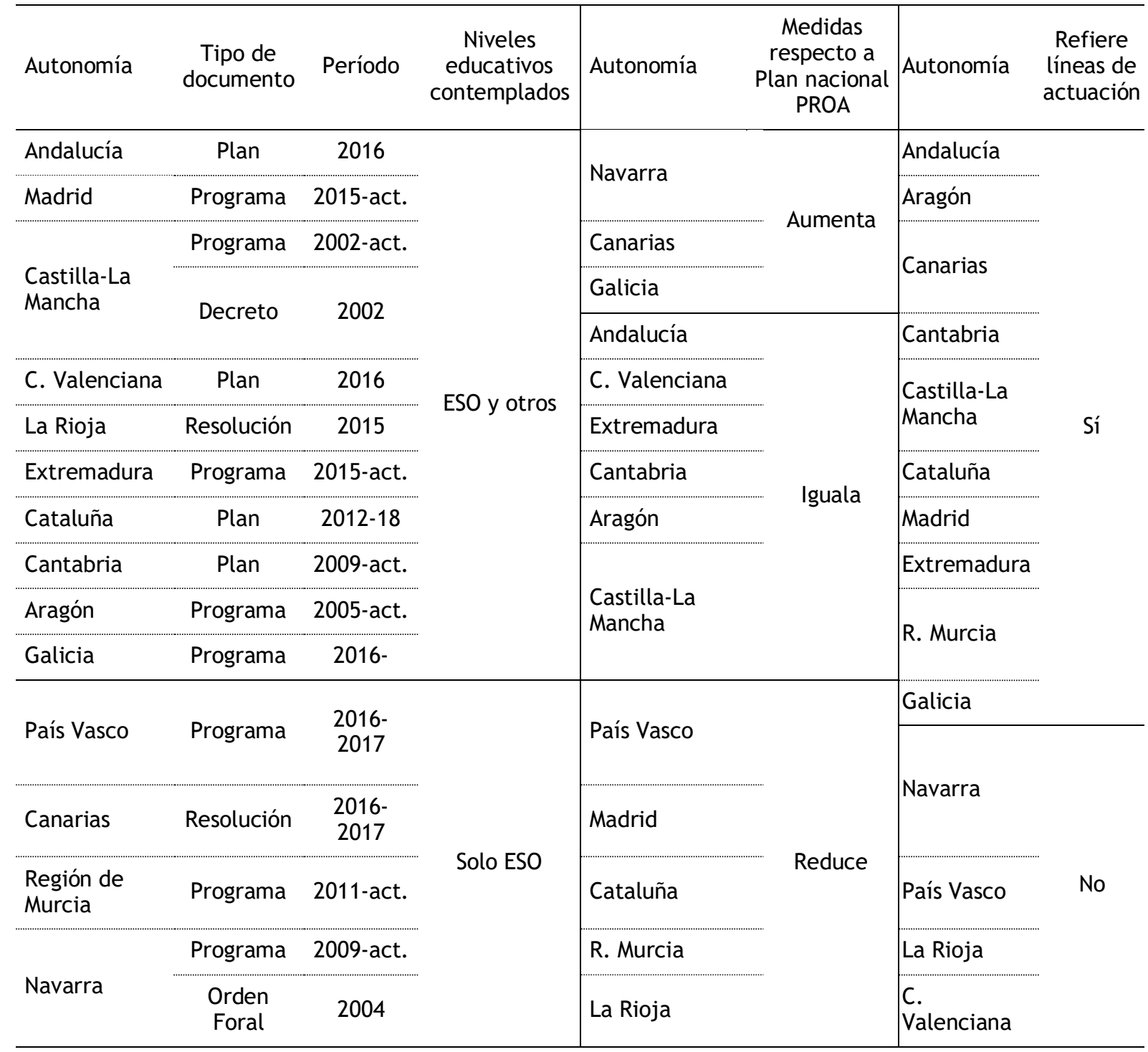

Fuente: Elaboración propia.

Nota: En el resto de autonomías no hay: Asturias, Islas Baleares y Castilla y León. 
En la mayoría de las comunidades autónomas encontramos programas o medidas contra el fracaso, si bien en menor medida contra el abandono. No obstante, los profesionales entrevistados alertan de la insuficiencia de tener normativa o programa, si existe una clara falta de recursos, al cual nos podemos aproximar mediante el gasto público en educación.

\subsubsection{Evolución del gasto público en educación por autonomías}

En el análisis del gasto público en educación es frecuente considerar el gasto público por alumno en la enseñanza no universitaria, expresado en términos absolutos, frente a otros indicadores como dicho gasto expresado en porcentaje del PIB, ya que este último puede verse afectado por el crecimiento económico.

Tabla 12

Evolución del gasto público autonómico por alumno en enseñanza no universitaria (€) y variación (VA y \%), 2007 y 2015.

\begin{tabular}{lcccc}
\hline \multirow{2}{*}{ Autonomía } & 2007 & 2015 & \multicolumn{2}{c}{ Variación $2007-2015$} \\
\cline { 4 - 5 } & & & VA & $\%$ \\
\hline País Vasco & 6.786 & 6.437 & -349 & $-5,1$ \\
Asturias & 6.316 & 5.747 & -569 & $-9,0$ \\
Navarra & 6.153 & 5.731 & -422 & $-6,9$ \\
Cantabria & 5.970 & 5.644 & -326 & $-5,5$ \\
Extremadura & 5.250 & 5.595 & 345 & 6,6 \\
Galicia & 6.114 & 5.585 & -529 & $-8,7$ \\
Castilla y León & 5.673 & 5.372 & -301 & $-5,3$ \\
Islas Balears & 5.306 & 5.102 & -204 & $-3,8$ \\
La Rioja & 5.702 & 5.004 & -698 & $-12,2$ \\
Aragón & 5.236 & 4.891 & -345 & $-6,6$ \\
España & 5.233 & 4.743 & -490 & $-9,4$ \\
C. Valenciana & 4.966 & 4.628 & -338 & $-6,8$ \\
Canarias & 5.161 & 4.627 & -534 & $-10,3$ \\
Cataluña & 5.145 & 4.580 & -565 & $-11,0$ \\
Castilla-La Mancha & 5.693 & 4.545 & -1.148 & $-20,2$ \\
Región de Murcia & 4.785 & 4.545 & -240 & $-5,0$ \\
Andalucía & 4.528 & 4.220 & -308 & $-6,8$ \\
Madrid & 4.819 & 3.957 & -862 & $-17,9$ \\
\hline Distancia autonómica & 2.258 & 2.480 & 222 & 9,8 \\
\hline
\end{tabular}

Fuente: Contabilidad Nacional del INE.

Nota: Gasto público por alumno en enseñanzas no universitarias del sistema educativo, por tanto, excluida la formación ocupacional.

La Tabla 12 muestra cómo la disminución del gasto público por alumno en la enseñanza no universitaria en el período 2007-2015 es generalizada en todas las 
comunidades autónomas de España, oscilando en un intervalo que se extiende desde el 3,8\% en el caso de las Islas Baleares y el 20,2\% en Castilla-La Mancha. La media de España acumula casi un $10 \%$ de disminución $(9,4 \%)$. En términos absolutos, se aprecia una disminución acentuada del gasto público en educación por alumno.

Las distancias autonómicas en los dos años analizados son considerables, tendiendo al aumento $(9,8 \%)$. El primer puesto con mayor gasto lo ocupa en ambos años País Vasco, con 6.437 € en 2016; dato mucho mayor al que presenta la autonomía con menor gasto, Madrid, con 3957.

La correlación de este indicador con los resultados educativos y de AET no se da claramente en todas las autonomías, aunque sí se observa correlación positiva entre mayor gasto y menor abandono en varias autonomías como País Vasco o Navarra; en otras con alto gasto, como Extremadura, o con bajo gasto, como Madrid, la relación es contraria.

\section{Discusión}

Los análisis realizados en los apartados anteriores permiten obtener varias conclusiones sobre la evolución de las desigualdades educativas y la distinta respuesta institucional, al tiempo que se describen los diferentes modelos o estrategias desarrolladas por las autonomías como respuesta institucional educativa.

En cuanto a la evolución de los indicadores de resultados educativos, de gestión y de gasto público, se ha visto que la mayoría de los resultados presentan mejora generalizada en todas las autonomías (AET, nivel de estudios de la población, tasa de idoneidad y de escolarización, PISA en lectura), si bien, otros lo hacen solo en algunos territorios (PISA matemáticas y ciencias). Respecto a la gestión, en todos los territorios se reduce el número de alumnos por aula y el gasto en educación, siendo muy dispar la evolución del alumnado en centros públicos. Asimismo, la evolución de los dos indicadores de contexto económico varía según autonomía, tanto la tasa AROPE como el PIB per cápita.

Las tendencias en la desigualdad educativa se mueven, en la mayoría de los indicadores de resultados, hacia la reducción de las distancias autonómicas (AET, tasa de escolarización, tasa de idoneidad, PISA matemáticas, PISA ciencias) o a su estancamiento (PISA lectura); también en los indicadores de gestión se ve confluencia (alumnos por aula, alumnado en centros públicos). No obstante, aumentan las distancias autonómicas en el gasto público, llegando casi a doblar el gasto de País Vasco al de Madrid en 2016. Los indicadores de contexto económico siguen la misma tendencia que el gasto público, aumentando las distancias en los valores de la tasa de exclusión y del PIB per cápita.

Respecto al compromiso autonómico con la política socioeducativa, manifestado a partir de documentación en planes, leyes o programas contra el abandono o el fracaso escolar, se han diferenciado cinco niveles de compromiso. El 
primero sería el de aquellas autonomías que cuentan con ambas políticas y en ellas reflejan alta cobertura (Andalucía, Extremadura y Aragón); el segundo, el de las que cuentan con las dos medidas, aunque solo son de alta cobertura contra el fracaso escolar (Cantabria y Castilla-La Mancha); en el tercero, estarían las autonomías que cuentan con los dos programas, si bien, con cobertura limitada (Murcia, Galicia, Rioja, Cataluña, Navarra y Canarias); el cuarto nivel sería donde solo se cuenta con el programa de abandono (Madrid, País Vasco y Valencia), y el quinto, el de aquellas que carecen de ambos programas (Asturias, Baleares y Castilla y León). No obstante, cabe mencionar que excepto Asturias y Madrid, el resto de las autonomías cuentan con medidas especiales para colectivos en desventaja social. Este nivel de compromiso no siempre se corresponde con una mayor eficacia del sistema educativo, pues hay comunidades con alto compromiso que presentan resultados educativos muy deficientes, como es el caso de Andalucía o Extremadura; o a la inversa, autonomías con deficiente política educativa en materia de planes o programas, que obtienen buenos resultados, como Madrid o País Vasco; si bien es cierto que en ambas autonomías el gasto en educación es de los más altos de España, al tiempo que presentan menor alumnado en centros públicos que la media española.

La combinación de las anteriores variables da como resultado la existencia de distintos modelos de gestión del sistema educativo según la comunidad autónoma que se trate, si bien se encuentran mediados por los niveles de riqueza y pobreza de cada territorio, así como por la estructura y diversidad demográfica. Las autonomías configuran sus políticas socioeducativas considerando esos aspectos, al tiempo que desarrollan diversas estrategias de gestión y grado de compromiso documental y económico. Siguiendo este conjunto de variables, se han diferenciado seis estrategias de respuesta institucional, con distintos niveles de eficacia y eficiencia.

1. Estrategia 1 (Navarra y País Vasco): es la que siguen algunas comunidades muy ricas en términos relativos, que presentan bajos niveles de compromiso documental y gasto en educación muy alto, junto a bajos niveles de alumnos en centros públicos. Es un modelo muy eficaz, pues obtienen muy buenos resultados educativos (bajas tasas de AET y altos niveles educativos de la población). Rioja y Galicia seguirían este modelo, aunque con resultados educativos cercanos a la media española.

2. Estrategia 2 (Madrid): se asemeja a la anterior, pues también obtiene buenos resultados, con porcentaje bajo de alumnos en centros públicos y bajo compromiso documental, si bien su nivel de gasto en educación es muy inferior a la media española. Se trata de la autonomía más rica de España y que ostenta un modelo muy eficiente.

3. Estrategia 3 (Cantabria): también es eficaz, pues obtiene resultados muy buenos, aunque con gasto en educación por encima de la media, cuenta con alto compromiso documental y elevado peso del alumnado en centros públicos.

4. Estrategia 4 (Extremadura): es también un modelo eficaz, aunque no eficiente, pues obtiene resultados en torno a la media española, a pesar de contar con un 
alto compromiso documental y de nivel de gasto en educación. Es una de las autonomías más pobres de España y aboga por un alto peso de alumnado en centros públicos.

5. Estrategia 5 (Andalucía): es un modelo ineficaz, pues a pesar de su alto compromiso documental, obtiene resultados deficientes. Es una autonomía de las más pobres, su nivel de gasto en educación es bajo y presenta un alto porcentaje de alumnos en el sistema público.

6. Estrategia 6 (Baleares): es una de las autonomías más ineficientes en política socioeducativa, basada únicamente en un alto nivel de gasto y carente de compromiso documental. Es una autonomía con riqueza en torno a la media española con tendencia al descenso del alumnado en centros públicos.

El resto de las autonomías presenta una combinación de los anteriores modelos o estrategias, dependiendo de sus niveles de riqueza y de respuesta institucional.

Como se ha visto, la diversidad de modelos y estrategias desarrollados en la política socioeducativa son muy amplias y variadas, estando en gran medida sesgadas por el componente económico, ya sea de riqueza o de pobreza de la población autonómica. Como señalase Calero (2007: 180), "una sociedad que quiera remover las desigualdades sociales de mayor entidad debe velar por que el proceso educativo sea lo más independiente posible de las condiciones socioeconómicas de partida". Para ello, se deben tener en cuenta otros factores que pueden incidir en los diferentes resultados educativos, tanto de índole socioeconómica (niveles de ocupación, tipo de empleo, sector de actividad...) como de diversidad en los centros educativos (población extranjera, colectivo gitano). Al igual que Rambla y Fontdevila (2015), el fortalecimiento de un sistema de becas y ayuda al estudio se torna esencial en este sentido.

Estas otras variables podrían explicar, en cierta medida, las causas de la ineficacia de algunos modelos vistos anteriormente, donde a pesar de contar con una política socioeducativa, con alto compromiso documental y algo gasto educativo, los resultados educativos siguen siendo bajos o medios. No obstante, también cabría explicar los distintos niveles de eficacia/eficiencia por motivos de gestión interna de la política autonómica o por la ausencia de verdaderas medidas estatales de corrección de las desigualdades educativas territoriales, las cuales se imputaban a la misma LOMCE por parte de los profesionales entrevistados, acusándola de segregadora y clasista.

Al margen de las causas, es cierto que los territorios autonómicos han mejorado sus resultados y reducido las distancias, si bien aún son amplias las desigualdades educativas entre ellos. Este hecho erosiona enormemente la cohesión social en España, pues el potencial del capital humano se puede ver condicionado por el territorio de residencia. En este sentido, coincidimos con Bayón-Calvo et al (2017) en la necesidad de dar continuidad al Programa de cooperación territorial para la reducción del AET, 
en mejorar el seguimiento y evaluación de las medidas y programas implementados, y en incrementar la dotación presupuestaria de los mismos.

\section{Referencias bibliográficas}

Bayón-Calvo, S., Corrales-Herrero, H. y Ogando Canabal, O. (2017). Los factores explicativos del abandono temprano de la educación y la formación en las regiones españolas. Investigaciones Regionales, 37, 99-117.

Becker, G.S. (1964). Human capital: A theoretical and empirical analysis, with special references to education. New York, Estados Unidos: National Bureau of Economic Research.

Briceño-Mosquera, A. (2011). La educación y su efecto en la formación de capital humano y en el desarrollo económico de los países. Apuntes de CENES, 30(51), 45-59.

Calero, J. (dir.) (2007). Desigualdades socioeconómicas en el sistema educativo español. Madrid, España: Centro de Investigación y Documentación Educativa (CIDE).

Escudero, J. M. (2005). Fracaso escolar, exclusión educativa: ¿de qué se excluye y cómo? Profesorado. Revista de currículum y formación del profesorado, 1(1), $1-24$.

Felgueroso, F., Gutiérrez-Domènech M. y Jiménez S. (2011). «Why school dropout remained so high in Spain in the last two decades? The role of the educational law (LOGSE)». Mimeo.

Fernández-Enguita, M., Mena, L. y Rivière, J. (2010). Fracaso y abandono escolar en España. Barcelona, España: Fundación La Caixa.

Foces, J. A. (2018). Educación y desigualdades territoriales en España. Cuadernos de pensamiento político, 60, 37-55.

Fundación FOESSA (2014). Precariedad y cohesión social. Madrid, España: Fundación FOESSA.

García, M. , Casal, J., Merino, R., y Sánchez, A. (2013). Itinerarios de abandono escolar y transición tras la ESO. Revista de Educación, 361, 65-94. doi: 10.4438/1988592X-RE-2011-361-135.

Gil-Lacruz, M. y Gil-Lacruz, A.I. (2006). Capital humano y capital social, implicaciones en el crecimiento económico. Revista del Ministerio de trabajo y Asuntos Sociales, 61, 93-104. 
González, M.T. (2017). Desenganche y abandono escolar, y medidas de re-enganche: algunas consideraciones. Profesorado. Revista de Currículum y Formación del Profesorado, 21(4), 17-37.

Guisán, M.C., Neira, I. y Aguayo, E. (1998). “Capital humano y capital físico en la OCDE, su importancia en el crecimiento económico en el período 1956-1990”. Documento de la serie Economic Development, n.26. 1

Hernández, M. (2010). El estudio de la pobreza y la exclusión social. Aproximación cuantitativa y cualitativa. Revista interuniversitaria de formación del profesorado, 69(24), 25-46.

Hernández, M. (dir.) (2019). Los modelos sociales autonómicos en el contexto español. Madrid, España: Consejo Económico y Social de España.

Martínez, J.S. (2017). La equidad y la educación. Madrid, España: Catarata.

Mincer, J. (1958). Investment in human capital and personal income distribution. Journal of Political Economy, 66, 281-302.

Mora, A.J. (2010). Determinantes del abandono escolar en Cataluña: más allá del nivel socio-económico de las familias. Revista de Educación, número extraordinario 2010, 171-190.

OCDE (1998). Human Capital Investment: An International Comparison. París, Francia: Organization for Economic. Centre for Educational Research and Innovation, OECD.

Rambla, X. y Fontdevila, C. (2015). Una oportunidad para evaluar las teorías del cambio: la estrategia europea contra el abandono escolar prematuro. Profesorado. Revista de Currículum y Formación del Profesorado, 19(3), 44-57.

Romero, E. y Hernández, M. (2019). Análisis de las causas endógenas y exógenas del abandono escolar temprano: una investigación cualitativa. Educación XX1, 22(1), 263-293. doi: 10.5944/educXX1.21351

Salido, O. y Martínez, J.S (2018). Equidad, igualdad de oportunidades y educación. En L. Ayala, $3^{\text {er }}$ Informe sobre desigualdad en España (pp. 123-147). Madrid, España: Fundación Encuentro.

Schultz, T. (1961). Investment in human capital. The American Economic Review, 51(1), 1-17.

Serrano, L. Soler, A. Hernández, L. y Sabater, S. (2013). El abandono educativo temprano: el caso español. Valencia, España: Instituto Valenciano de Investigaciones Económicas.

Serrano, L., y Soler, A. (2014). Evaluación del programa de cooperación territorial para la reducción del abandono temprano de la educación. Valencia, España: Instituto Valenciano de Investigaciones Económicas. 
Solano, J.C. (2008). La exclusión social a través de la igualdad de oportunidades educativas. En M. Hernández (Coord.), Exclusión social y desigualdad (pp. 105130). Murcia, España: Editum.

Villar, A. (Coord.) (2012). Educación y desarrollo: PISA 2009 y el sistema educativo español. Bilbao, España: Fundación BBVA.

Agradecimientos y financiación del artículo:

Al Observatorio de la Exclusión Social de la Universidad de Murcia (OES) y a todos los profesionales que participaron en las entrevistas.

Cómo citar este artículo:

Romero-Sánchez, E., Alcaraz-García, S. \& Hernández-Pedreño. M. (2020). Desigualdades educativas y respuesta institucional: una investigación desde la perspectiva territorial. Profesorado. Revista de Currículum y Formación de Profesorado, 24(1), 22-48. DOI: 10.30827/profesorado.v24i1.8834 